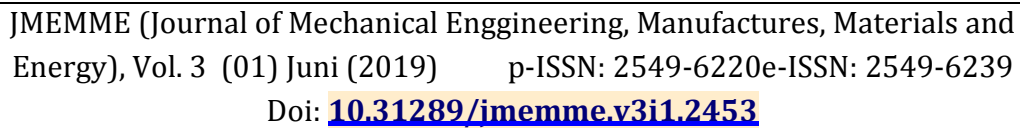

JMEMME (Journal of Mechanical Engineering, Manufactures, Materials and Energy)

\title{
PERFORMANCE OF FP 200 PVDF MEMBRANE EQUIPMENT IN POLYPHENOL PURIFICATION FROM PINK GUAVA JUICE WASTE
}

\author{
Lilis Sukeksi ${ }^{1,2) *}$, Che Rosmani Che Hassan ${ }^{3)}$, Nik Meriam Nik Sulaiman ${ }^{3)}$ \\ 1) Chemical Engineering Department, Faculty of Engineering, Universitas Sumatera Utara, \\ Jl. Almamater Kampus USU, Medam 20155, Indonesia \\ 2) Centre of Excellent Natural Product base on Technology, Universitas Sumatera Utara, \\ Jl. Dr. T. Mansur No. 9 Kampus USU, Medan 20155, Indonesia \\ 3) Chemical Engineering Department, Fakulty of Engineering, Universiti Malaya, 50603, Kuala \\ Lumpur, Malaysia \\ Diterima: 22-04-2019 ; Disetujui: 24-06-2019 ; Diterbitkan: 30-06-2019 \\ *Corresponding author: lilissukeksi79@yahoo.com
}

\begin{abstract}
Juice processing plants, such as pink guava, still contain substances that have economic value such as anti-oxidant polyphenols. The polyphenols recovery process is carried out using a membrane separation FP 200 PVDF type, by reason of the membrane separation process without using heat to avoid damage from the polyphenols structure. The duration of the recovery process affects the performance of flow rate of the membrane, there is a decrease in the flow rate of $0.033 \mathrm{ml} / \mathrm{min}$ for the process in TMP $1 \mathrm{bar}$ and $0.038 \mathrm{ml} / \mathrm{min}$ and $0.044 \mathrm{ml} / \mathrm{min}$ for TMP 2 and 3 bars respectively. Cleaning is done to improve membrane performance, cleaning using $\mathrm{HNO}_{3}$ is more effective than just using clean water. The process of recovery of polyphenols was carried out at 1 bar TMP and resulting 54\% recovery of polyphenols. After the cleaning process \% recovery of polyphenols decreases compared to the results of the first recovery. SEM shows the absorption of polyphenols and other contaminants in the pores of the membrane, thus affecting the performance of the membrane.
\end{abstract}

Keywords: membrane separation, polyphenols, flow rate, cleaning and recovery

How to Cite: Sukeksi, L., 2019, Performance of FP 200 PVDF Membrane Equipment in Polyphenol Purification From Pink Guava Juice Waste 3, JMEMME (Journal of Mechanical Enggineering, Manufactures, Materials and Energy), (01): 45-56 
Sukeksi, L., Performance of FP 200 PVDF Membrane Equipment in Polyphenol Purification

\section{INTRODUCTION}

Consumption of fruits and vegetables tends to increase in recent years due to its nutritional content. Some of the fruits and vegetables are processed into juice to avoid damage from the fruit, ease of transportation and easier to consume. However, processing the juice will produce large amounts of waste which still contains a large number of nutrition components such as polyphenols (Rice-Evans, 1997), (Luximon-Ramma, 2003). Polyphenol compounds have become a big concern regarding the benefits to human health. For example, the use of waste generated from the processing of pink guava fruit, especially in tropical countries, can also produce natural additives such as polyphenol components (Schieber, 2001), (Petrson, 1998), (Jimenez-Escrig, 2001) and (Ferkanich, 2000).

(Arima, 2002) found that red guava had the highest total content of polyphenols and vitamin C compared to lychees and papaya as tropical fruits. Guava also generally contains sugar, protein, a combination of minerals with antioxidants such as polyphenols (Luximon-Ramma, 2003), (Mercadante, 1999)), (Iwu, 1993), lutein, zeaxanthine, lycophene (Tee, 1997) and pectin (Sidhu, 2012). The chemical composition of fruit generally depends on cultivar, maturity phase, and season (Hui, 2006). Other study shows that the extensive value of wastes after the pink guava processing from fruit juice industry yet contain valuable compounds (Kong et al.,2010). Recent study indicates that pink guava processing wastes contain some polyphenols such as quercetin, epigenin, gallic acid, tannins and $ß$-carotene (Arima, 2002), (Sukeksi L. S., 2016), which can be effected by steam blanching (Kong, 2010). The first way to get polyphenols from red guava waste is to isolate polyphenols by using the extraction process. Solid waste of pink guava is extracted using water as a solvent like the research that has been done (Sukeksi L. C., 2016).

To obtain polyphenols from extract pink guava waste must use a separation process such as distillation, evaporation and separation membranes. Polyphenols are antioxidants that have double bonds in their chemical structure so that they are very easily broken down due to heat in the separation process such as distillation processes. Therefore, for the process of separation and purification of polyphenols substances should use a membrane separation equipment. The membrane technology is an emerging technology and it can be used in many separations processing, (Mulder, 1996) has defined membrane as a selective barrier between two phases. The classification of industrial membrane process is based on the size of the materials used. Therefore, technologies such as micro filtration, ultra filtration and nano filtration can be used for separation by size, related to its molecular weight. (Beltran, 2008) explored on the recovery of antioxidants from grape products using super critical fluids and membrane technology. They found that membrane technologies are a decent procedure for separation of polyphenols that are contained in grape seeds. In summary, the separation is to achieve fraction with different molecular 
weight, different polyphenols content and different antioxidant activity. The purpose of this research is to find out various aspects of the performance tubular Hydrophilic Polyvinylidene Fluoride (PVDF) membrane type FP 200 with nominal molecular weight cut off (MWCO) 200,000.

\section{MATERIALS AND METHODS}

\section{Raw Materials and Chemicals}

The pink guava fruit processing wastes were collected from the juice processing factory in Sitiawan, Perak in Malaysia. The samples were collected randomly from siever, refiner, and decanter waste tanks and packed immediately into a closed plastic container and stored in the freezer (ACSON International Refrigerator) to prevent mildew or oxidation. The time between freezing and analysis of the sample was 12 weeks. It is based on the principle presumption of the quality of the bulk sample to give a representative quality of all the wastes.

A solvent for extraction of polyphenols was water which purified by an Elga Micromeg deionizer.1.5 g of each sample with $25 \mathrm{ml}$ of solvent were mixed and shake at ambient temperature for 2 hours. Afterward, the extracts were centrifuged by MediSpin centrifuge and filtered by Whatman filter papers. Clear extract was used for analyzing the total polyphenols content (TPC). FolinCiucalteu's phenol reagent, gallic acid standard (provided by Sigma-Aldrich, Great Britain) and sodium carbonate (Na2CO3) (provided by Fluka, Germany) with purity of 98-99\% were used for analyzing of TPC.

\section{Sample Preparation}

Polyphenols in the pink guava waste were extracted using water as solvent with 10 liter of solvent and 1,200 $\mathrm{g}$ of pink guava waste. The mixture of waste and water is constantly blended for 10 minutes until uniform slurry or solution was obtained using a warring blender. After 12 hours, the aqueous extract was separated from the solid by removing the upper solution to reduce the suspended solid content.

\section{Equipment}

In first step, a type commercially tubular PVDF membrane type FP 200 with nominal MWCO 200,000 (supplied and manufactured by PCI Membrane Technology) with high solvent resistances was used to recover polyphenols as seen in Figure 1. The equipment also had a flow rate indicator and a valve for pressure control. Prior to use, the membrane was soaked overnight in water to eliminate impurities left from the mechanized process or additives used for stabilization and wetting of the membranes. All material of equipment such as, pump, feed reservoir and all connection tubing are used base of stainless steel material. Membrane separation experiment was carried out with continuous retentate recycling. The result permeate was continuously removed, until the desired volume concentration ratio (VCR) was achieved. 


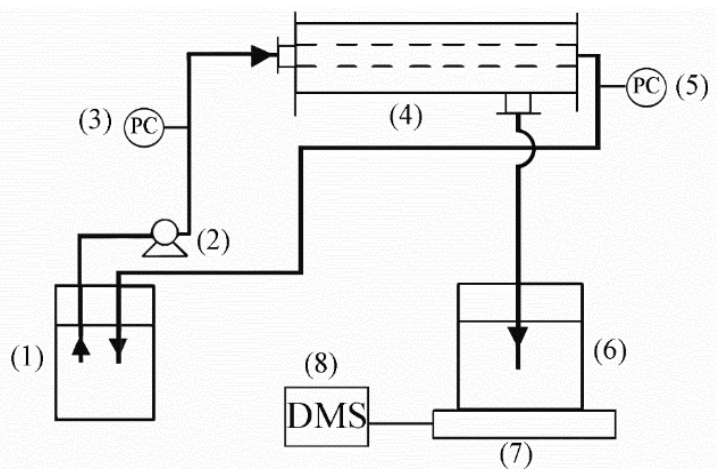

Fig 1. Scheme of membrane equipment. (1) feed reservoir, (2) a diaphragm pump, (3) inlet pressure gauge, (4) tubular membrane with the double of membrane housing $32.5 \mathrm{~cm}$ (The membrane molecular weight cut off (MWCO) are 200,000 and the diameter is $1 \mathrm{~cm}$ with $150 \mathrm{~cm}$ of length), (5) outlet pressure gauge, (6) permeate collection reservoir, (7) balance AND GF 400 (model 77200-6, Japan) and (8) data logging. Master flex flexible tubing was used for all connections.

The steps involve in experiment were initial water flushing to remove the storage solution, measurement water flux then filtration of feed pink guava waste processing solution and finally, flushing and cleaning with water. In operation stage, the feed stream was pumped through the tubular membrane. The retentate, including species excluded by the membrane pores, continues through the recirculation loop back to the feed while permeate, including solvent and solutes transported through the membrane pores, was collected on the shell side of the tubular membrane and to the permeate reservoir. Ultra filtration (UF) tubular membrane was started up with the permeate ports closed, allowing the cross velocity to be established prior to permeate withdrawal, with both of the feed inlet valve and the retentate wide open. After the pump was turned on, the inlet valve was opened and the retentate valve was slowly closed to establish the preferred condition. As the permeate volume increases, the concentration of the polyphenols should increase as well. UF experiment was carried out with continuous retentate recycling.

The involved steps in this experiment were: First cleaning, Determine of Flux, Recovery of Polyphenols and Second cleaning. Cleaning involved by water flushing for ten minutes and nitric acid $0.3 \%$ for 30 minutes followed by water flushing again for ten minutes, to remove impurities left from the mechanized processing or additives used for stabilization. The end of water flushing, measured flow rate by using data storing from the data lodging. In addition, the volume of permeate ( $\mathrm{Vp}$ ) of pure water were collected from feeding sample before recovering polyphenols. Alternatively, for setting the preferred TMP (1, 2 and 3 bar) the pump had switched on and inlet valve was opened while retentate valve was closed slowly. Processing experiment was carried out with continuous retentate recycling until VCR $=4$ was achieved. All collected data record by a data logger. The samples from permeate and retentate used to analyze Total Polyphenols Content (TPC). The second cleaning procedure was same as the first cleaning procedure. The membranes were cleaned at TMP 1, 2 and 3 bars for higher efficiency. All the processing procedures were repeated for three times. 


\section{Measurement of Total Polyphenols Content}

Total polyphenols content (TPC) was measured by the colorimetric FolinCiocalteau assay. This method combined $200 \mu \mathrm{l}$ of extract sample and $1500 \mu \mathrm{l}$ of $0.25 \mathrm{~N}$ Folin-Ciocalteau reagent which mixed well with a Vortex (model M 37610-33, supplied by Barnstead International in Malaysia). Then, the mixture reacted with $1500 \mu \mathrm{l}$ of $1 \mathrm{~N}$ $\mathrm{Na}_{2} \mathrm{CO}_{3}$ solution for 3 minutes at $22^{\circ} \mathrm{C}$. Alternatively, the solution was incubated at ambient temperature in the dark place for 90 minutes to form a mix of blue oxides. The absorbance was taken at 765 $\mathrm{nm}$ by a spectrophotometer (Thermo Spectronic Genesys 20 model 4001/4, made in USA, 2008) to optimum results. Because of a wide spectrum of polyphenols compounds, gallic acid with calibration curve range between 0.1-1.2 $\mathrm{mg} / \mathrm{ml}$ was also used as a standard unit for TPC determination. In addition, adequate dilution was conducted if the absorbance value measured was over the linear range of the standard curve.

\section{RESULT AND DISCUSSION}

\section{Effect of Time and Flow rate of} Permeate on Membrane Performance

These set of experiments were performed to determine the membrane performance from PVDF membrane FP 200. The membrane performance was conducted based on the effect of Total Membrane Pressure (TMP) on permeate flow rate. Figure 1 shows flow rate (ml/min) of total recovered polyphenols at different TMP within 100 minutes by membrane FP 200. The collected permeate volume during recovery of pink guava processing wastes increased linearly at different of TMP. Nevertheless, the permeate flow rate collected decreased for higher TMP value by using membrane FP 200. In the TMP 1 bar the initial flow rate of permeate is 25 ml per minute, the initial TMP 2 bar reaches $30 \mathrm{ml}$ per minute while the TMP 3 bar initial flow rate is around $24 \mathrm{ml}$ per minute. The steady state condition is reached for TMP 1 bar is at 10 minutes with a flow rate of $22 \mathrm{ml}$ per minute, a decrease in flow rate of about $3 \mathrm{ml}$ from the initial flow rate or around $12 \%$. For TMP 2 bar, the steady state is reached at 17 minutes with a flow rate of permeate per minute of $19 \mathrm{ml}$, a decrease of about $11 \mathrm{ml}$ from the initial flow rate which is around 37\%. Meanwhile in the TMP 3 bar the steady state was reached at 32 minutes with permeate flow rate of 14 $\mathrm{ml}$, there was a decrease in volume of 10 $\mathrm{ml}$ from the initial flow rate or about 42 $\%$.

(Tasselli, 2007) reported the effects of pressure on the steady state permeate flux. Membrane processing at constant values of flow rate $40 \mathrm{l} / \mathrm{h}$, temperature is $25^{\circ} \mathrm{C}$ and suspended solids concentration is $10 \%$. The permeate fluxes pointed to a linear increase with pressure at lower pressures meanwhile at higher pressure the permeate flux approach a limiting value independent to further increase in pressure. The point was, when the highest permeate flux occurred at $75 \mathrm{kPa}$ ( 0.75 bar) and it is considered as the best pressure. This value is in excellent agreement with 85 $\mathrm{kPa}(0.85$ bar) that was already reported 
by (Cassano, 2008) for kiwi fruit juice UF using PVDF tubular membranes.

Figure 2 also shows in TMP 1 bar $\mathrm{R}^{2}$ is 0.02097 , and at TMP 2 bar $\mathrm{R}^{2}$ is 0.18434 while for TMP 3 bar $\mathrm{R}^{2}$ is 0.38270 , this shows that the membrane operating process in TMP 1 bar and 2 bar has a very weak correlation. This means that the duration of the separation process does not significantly affect to the flow rate or volume permeate. Meanwhile in the TMP 3 bar, the value of $\mathrm{R}^{2}$ shows that the correlation is quite influential between the duration of the separation operation process with the flow rate of the permeate. The linear regression equation for TMP 1 bar is $\mathrm{y}=$ $-0.118 \mathrm{x}+21,364$, the equation for TMP 2 bar is $y=-0.0399 x+20.141$, while for TMP 3 bar is $y=-0.0598 x+17,177$. The three equations have a minus value, which means there will be a decrease in the flow rate for the duration of the processing time.

(Cassano, 2008) founded the effect of TMP on the steady state of permeate flux which show a linear increase with TMP at lower pressures. Meanwhile at higher pressures the permeate fluxes approach a limiting value independent of further increases in TMP. Besides that, from the picture above, it can be seen that for each separation process for TMP 1 bar, TMP 2 bar and TMP 3 bar show a decrease in flow rate. For TMP 1 bar after steady state conditions are reached at 10 minutes the flow rate of $22 \mathrm{ml}$ per minute drops to $19 \mathrm{ml}$ per minute (13.6\%) for 90 minutes of the separation process. This means a decrease in flow rate of $0.033 \mathrm{ml}$ per minute. In the TMP 2 bar and 3 bars the reduction in the flow rate of each mass is
$16 \%$ and $14 \%$ for 90 minutes the separation process. This means a decrease in flow rate of $0.038 \mathrm{ml}$ per minute for TMP 2 bars and 0.044 for TMP 3 bars.

Since TMP act as a driving force for permeation flux, the rate of permeation flux will increase when the value of TMP increase. But the rate at which membranes foul by deposition of colloidal material is essentially controlled by the rate of removal in deposited materials. At high TMP, the rate of deposition would be high and the high-pressure would compress the rejected solutes into a thicker and denser fouling layer. Obviously it will cause high fouling effect (Alvarez, 1996). Permeation flux will increase with small increase of TMP, but will be independent when higher pressure is applied according to (Jiratananon, 1996) and (Wilson, 1982).

(Song, 1998) reported that if the applied pressure is higher than critical pressure it can be ordered to hold the particle on the membrane surface. The fundamental of membrane fouling is caused by the non-equilibrium of membrane separation, where the applied pressure is higher than critical pressure. The effect of washing on the flow rate on membrane performance. 


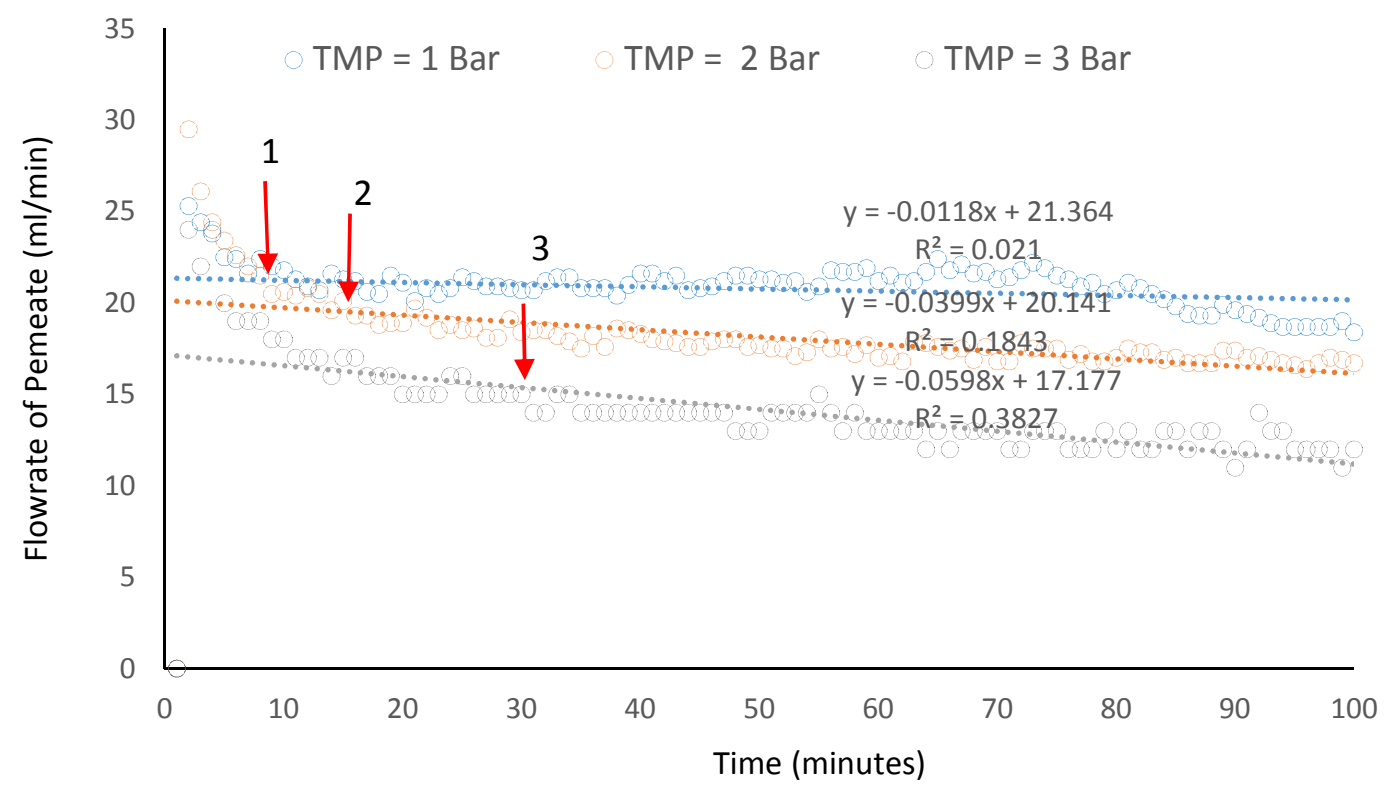

Figure 2. Flow rate of Permeate of polyphenols extract vs time separation

\section{Effect of Cleaning on Permeate Flow Rate on Membrane Performance}

During recovery of polyphenols severe fouling of the membrane occurs, thus affecting the performance of the membrane processing. Fouling could reduce the permeate fluxes therefore it is necessary to regenerate the membrne. To regenerate the membrane, cleaning or washing is needed. The effect of chemical cleaning on permeate flow rate was evaluated based on the differences between first and last permeate flow rates during polyphenols recovering. Figure 2 shows the effect of cleaning on the permeate flow rate of membrane FP 200 at different TMP (1-3bar).

From the figure 3 it can be seen that, the permeate flow rate pure water by using new membrane FP 200 at TMP 1 bar (A) was $65 \mathrm{ml} / \mathrm{min}$, at TMP 2 bar and 3 bar were $112.75 \mathrm{ml} / \mathrm{min}, 163.8 \mathrm{ml} / \mathrm{min}$ respectively. The first permeate flow rate of extract polyphenols at TMP 1 bar (B) was $25 \mathrm{ml} / \mathrm{min}$ and the permeate flow rate of extract polyphenols decreases to be $17 \mathrm{ml} / \mathrm{min}$ (C) after 180 minutes' membrane processing. Decreasing permeate flow rate of sample is about $0.044 \mathrm{ml} / \mathrm{min}$. The first drop of permeate flow rate was because of blocking of membrane pores. Washing the membrane using water as a cleaner agent result in an increase in the flow rate of water to be $22 \mathrm{ml} / \mathrm{min}$ (D). The cleaning continued by using $\mathrm{HNO}_{3}$ and the water permeate flow rate increase (E) to be 36 $\mathrm{ml} / \mathrm{min}$. There was a decrease in the water flow rate of $45 \%$ from the initial water flow rate after the separation process of the extract of polyphenols which was followed by the washing process using water and $\mathrm{HNO}_{3}$ as a cleaning agent. It can be seen from the Figure 3 that all phenomenon for membrane FP 200 at different TMP 1, 2 and 3 bar have similar effect. 
Sukeksi, L., Performance of FP 200 PVDF Membrane Equipment in Polyphenol Purification

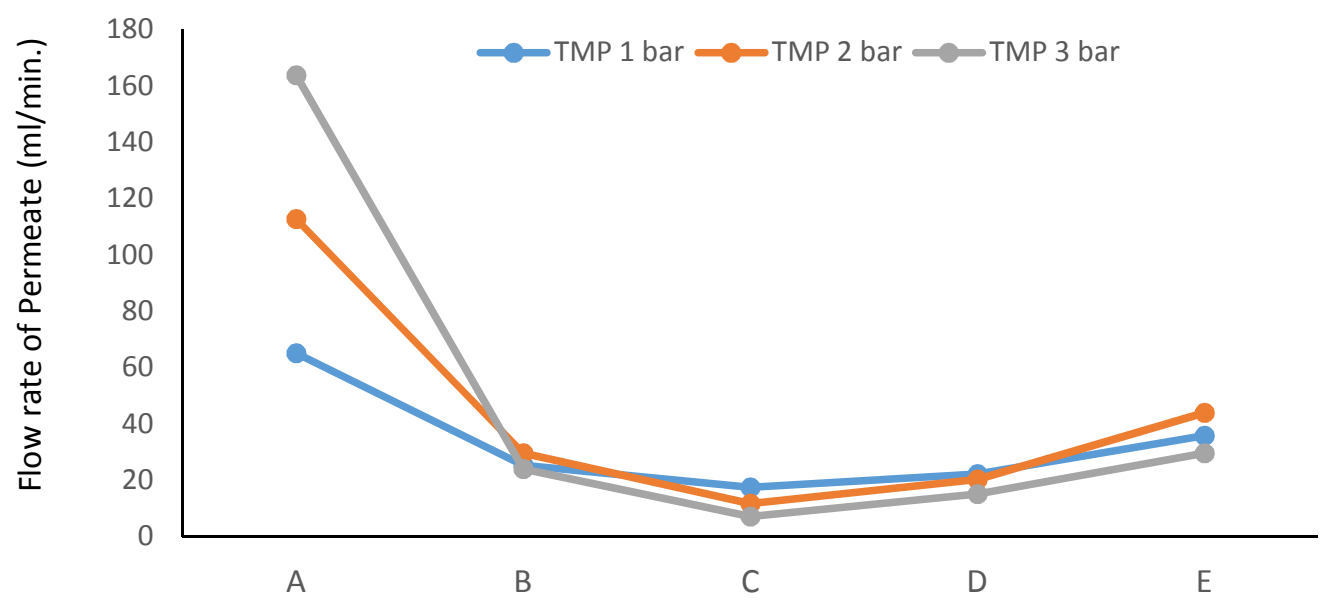

Figure 3 Effect of cleaning water and chemical to permeate flow rate at TMP 1 bar until 3 bar

The cleaning agent water and $\mathrm{HNO}_{3}$ have significant influence the performance of membrane FP 200, but has little effect on changes in TMP. This means that the separation process of extract polyphenols is better done at the TMP 1 bar.

As already mentioned before permeate flow rate decreases with increasing times of recovery processing. However micro porous membrane FP 200 is subjected to severe fouling resulting in decreases of permeates flow rate and flux decline. Fouling of the membrane surface and its pores because of polyphenols and another contaminant. In the cleaning step where water was used to remove labile polyphenols and others contaminant from the membrane surface. The cleaning will result increase of the membrane performance. After cleaning using $\mathrm{HNO}_{3}$ performing membrane was better because acting $\mathrm{HNO}_{3}$ to remove deposit and others contaminant.

Membrane pores would absorb of polyphenols and resulting decrease performance of membrane with times. The pores of membrane are more likely to be blocked partially and degree of pore blockage depends on the shape and the relative size of the particles and the pores (Song, 1998). Increasing TMP will result in increasing of materials adsorb to the pores of membranes. After cleaning procedure some or all caused of formation and growth of the cake layer on the membrane surface will be reduced.

(Blanpain-Avet, 2004) conducted analysis of membrane performance and cleaning efficiency. He found that membrane performance was kept stable over the ten cycles cleaning. Cleaning efficiency in term of flux recovery did not decay over the cycles. The hydraulic cleanness was not achieved which led to the build-up of an irreversible residual fouling stabilizing. (Rektor, 2004) decided that permeate flux and pressure behavior was agreeing with this results. Steady state permeates flow rate values increased by increased of TMP or applied pressure. It also correlated the flux decay 
is more pronounced at higher of TMP value.

\section{Recovery of Polyphenols Performance at TMP 1 bar}

Figure 4 shows the changes in recovery of polyphenols as a function of the permeate volume in five steps at TMP $=1$ bar. Recovery of polyphenols increased from $35 \%$ to $54 \%$ according to the increased volume of extract of polyphenols from $300 \mathrm{ml}$ to $3,000 \mathrm{ml}$. The overall results as can be seen in Figure 4, the decreases in the recovery of polyphenols from the first step until the fifth step was $54 \%$ to $37 \%$ for total recovered volume $(15,000 \mathrm{ml})$. The concentration of polyphenols in permeate in every $300 \mathrm{ml}$ volume of permeate which increased as a function of permeate volume. The recovery of polyphenols after the first step, the concentration of polyphenols kept decreasing until reaching to step five. This pointed out that adsorption of polyphenols at first step caused fouling, leading to a decrease of the polyphenols content from $35 \%$ to $31 \%$ at first step to second step of the processing. It shows that the membrane was effective for the removal of polyphenols from model solutions. By using this membrane, $54 \%$ of polyphenols could be removed for first step. After washing for five times the recovery of polyphenols to be $38 \%$, or a decrease in recovery of polyphenols by $16 \%$.

According to (Giovanelli, 1993), the UF membrane does not cause any remarkable decrease in polyphenols content of apple juice during the clarification procedure (only 12\%). This is in agreement with our measurement that after processing at first step the falling of polyphenols content do not have a significantly difference between the next steps. It can be explained that this decreasing at first step is because of pore blocking on membrane and the further deposition of particles on the membrane surface will form a cake layer.

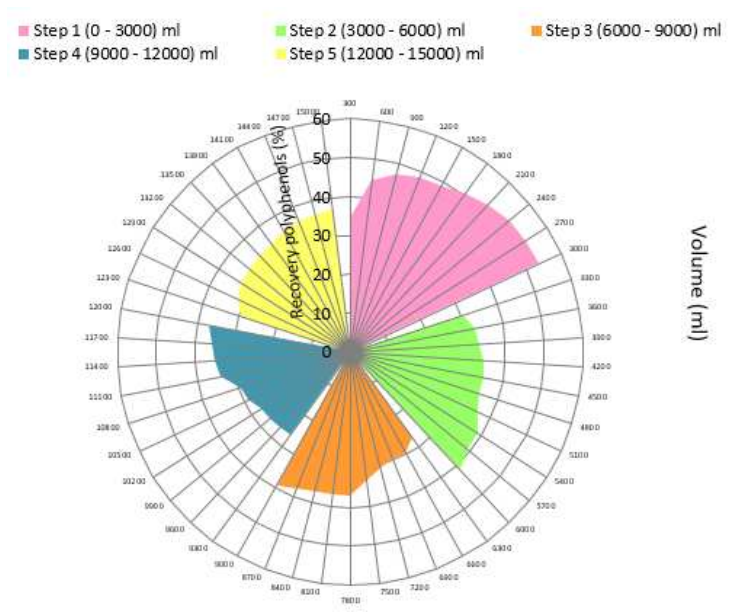

Figure 4. Recovery of polyphenols (\%) vs volume of permeate at five washing times

\section{SEM (Scanning Electron Micrograph)}

Figure 5 shows analysis of the membranes by SEM revealed the membrane microstructure. Figure 5A shows the new membrane microscopic shape FP 200. As seen, the membrane pores are show no fouling but they have some impurities on it. After recovery polyphenols processing with pink guava wastes extract, the membrane surface was again analyzed by SEM as shown in Figure 5B. It can be seen that some of pores fouled by turbid ingredients and many contaminants particle adsorbed on the surface of membrane.

The data from Figure 2, 3 and 4 correlating with Figures $5 \mathrm{~B}$, that strongest fouling was because of polyphenols and some contaminant, that adsorb on the membrane pores. Washing with water and chemical $\mathrm{HNO}_{3}$ can removed some of cakes layer and decrease the fouling. 
(Yan, 2009) Remarked application of the $\mathrm{AL}_{2} \mathrm{O}_{3}$ to the PVDF tubular membrane as antifouling for oily wastewater treatment. They found that $\mathrm{AL}_{2} \mathrm{O}_{3}$ could reduce amounts of contaminants adsorbed on the adapted membrane. Fouled membranes SEM analysis can also confirm this conclusion in qualitative.

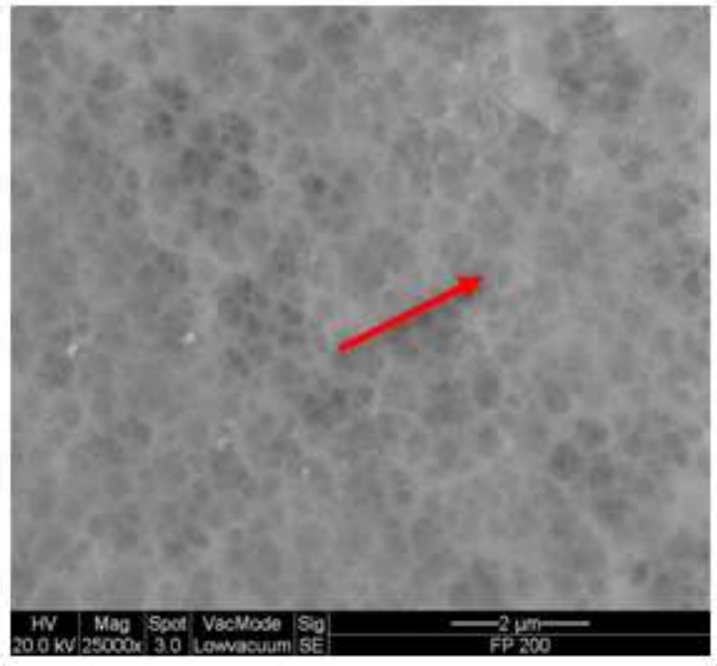

(a)

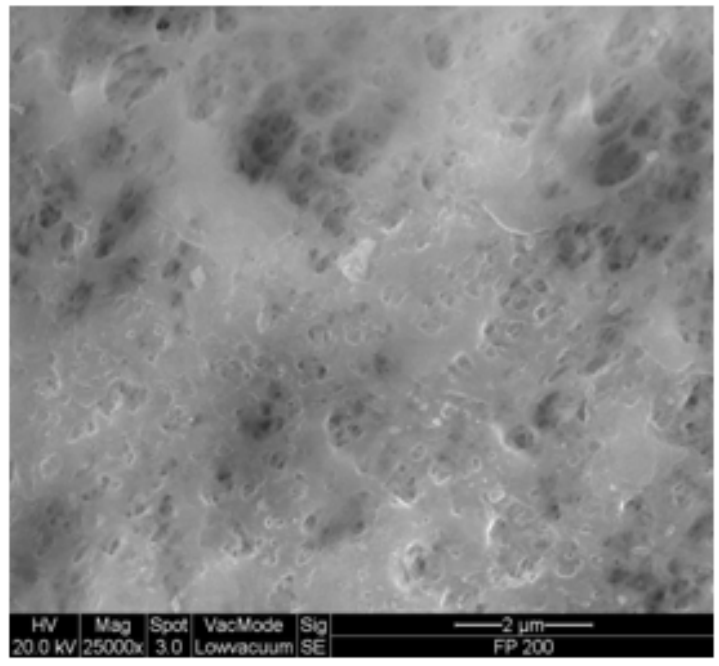

(b)

Figure 5. SEM images of membrane FP 200: (A) new membrane (25000 x); (B) processed membrane (30000 x)

\section{CONCLUSIONS}

From the results of the discussion it can be concluded that operating time affects the flow rate of permeate on membrane performance. The steady state process is achieved in 10 minutes for TMP 1 bar, 17 minutes for TMP 2 bars and 32 minutes for TMP 3 bars. In TMP 1 and 2 bar the duration of the separation process does not significantly affect the process flow rate, while for the TMP 3 bar has little effect. The three linear equations obtained by the relationship between flow rate and time are negative, this indicates that membrane performance in this case the flow rate of permeate decreases with increasing operating time.

The cleaning effect of membranes on membrane performance shows that washing affects the increase in membrane performance. Washing using $\mathrm{HNO}_{3}$ as a cleaning agent is more effective at improving membrane performance than cleaning using only clean water.

The best performance of the three TMPs used is in the TMP 1 bar. Recovery polyphenols in the TMP 1 bar show, with increasing time it will also increase the results of the polyphenols obtained. The highest recovery polyphenols were $54 \%$. The process of recovery polyphenols also clearly affects membrane performance by decreasing the percentage of initial polyphenols obtained after the cleaning process.

From the results of SEM, it can also be seen clearly that the decrease in membrane performance is due to the absorption of polyphenols and various contaminants. 


\section{REFERENCES}

Alvarez, V. A. (1996). Micro filtration of apple juice using inorganic membranes. Process optimization and juice stability. Canadian Journal Chemical Engineering, 74, 156-162.

Arima, H. D. (2002). Isolation of Antimicrobial Compounds from Guava (Psidium Guajava L.) and their structural elucidation. Biotechnology and Biochemistry, 66, 1727-1730.

Beltran, S. S. (2008). Recovery of antioxidants from grape products by using supercritical fluids and membrane technology. Electronic Journal of Environmental, Agricultural and Food Chemistry, 7 (8), 3270-3278.

Blanpain-Avet, P. M. (2004). The effect of multiple fouling and cleaning cycles on a tubular ceramic microfiltration membrane fouled with a whey protein concentrate (membrane performance and cleaning efficiency). Food and Bio Products Processing, 82, 231-243.

Cassano, A. M. (2008). Study of fouling mechanism in pineapple juice clarification by ultrafiltration. Journal Desalination, 212, 15-27.

Ferkanich, D. Z. (200o). Prospective Study of Fruit and Vegetable Consumption and Risk of Lung Cancer Among Men and Women. Journal of the National Cancer Institute, 92 (22), 1812-1823.

Giovanelli, G. R. (1993). Apple juice stabilization by combined enzyme membrane filtration process. Journal Technology Food, 26.

Hui, Y. H. (2006). Handbook of Fruits and Fruit Processing. Blackwell Publishing.

Iwu, M. M. (1993). Handbook of African Medicinal Plants.

Jimenez-Escrig, A. R.-C. (2001). Guava Fruit (Psidium Guajava L.) as a New Source of Antioxidant Dietary Fiber. Journal Agriculture Food Chem., 49 (11), 54895493.
Jiratananon, R. a. (1996). A study of fouling in the ultrafiltration of passion fruit juice. Journal Membrane Science, 111, 39-48.

Kong, K. W. (2010). Effect of steam blanching on lycopene and total phenolic in pink guava puree industry by-products. International Food Research Journal, 17, 461-468.

Luximon-Ramma, A. B. (2003). Antioxidants actions phenolic and vitamin $C$ contents of common Mauritian exotic fruits. Journal of the Science of Food and Agriculture, , 496-502.

Mercadante, A. Z. (1999). Carotenoids from Guava (Psidium Guajava L.): Isolation and Structure Elucidation. Journal Agriculture Food Chemistry, 145-151.

Mulder, M. (1996). Basic Principles of Membrane Technology. Dordrecht, Boston, London: KLuwer Academic Publisher.

Petrson, J. (1998). Research, Flavonoid: Dietary Occurrence and Biochemical Activity Nutrition. pp. 1995-2018.

Rektor, A. P.-M. (2004). Application of Membrane Filtration Methods for Must Processing and Preservation. Desalination, 162, 271-277.

Rice-Evans, C. A. (1997). Antioxidant Properties of Phenolic Compounds. . Trends in Plant Science, pp. 152-159.

Schieber, A. S. (2001). By-Product of Plant Food Processing as a Sources of Functional Compounds. Trends in Food Science and Technology, pp. 401-413.

Sidhu, J. S. (2012). Tropical Fruit II: Production, Processing and Quality of Guava, Lychee and Papaya. In N. S. Sinha, Handbook of Fruits and Fruit Processing (Second Edition ed.). UK: Wiley.

Song, L. (1998). Flux decline in cross flow microfiltration and ultrafiltration: mechanisms and modelling of membrane fouling. Journal of membrane science, 139, 183-200.

Sukeksi, L. C. (2016). Polyphenols Recovery from Tropical Fruits (Pink Guava) Wastes via 
Sukeksi, L., Performance of FP 200 PVDF Membrane Equipment in Polyphenol Purification

Ultra-Filtration Membrane Technology Application by Optimum Solvent Selection. Iranian Journal Chemical Engineering, 35 (3).

Sukeksi, L. S. (2016). Characterizations and Extraction of Polyphenols from Residual Pulp of Pink Guava as Source of Antioxidants. Journal of Engineering and Applied Sciences, 11 (8), 5209-5216.

Tasselli, F. C. (2007). Ultrafiltration of kiwifruit juice using modified poly (ether ether ketone) hollow fiber membranes. Journal Separation and Purification Technology, 57, 94-102.

Tee, E. S. (1997). Nutrient Composition of Malaysian Food Kuala Lumpur. Institute for Medical Research.

Wilson, C. W. (1982). Determination of Organic Acids and Sugars in Guava (Psidium Guajava L). Journal Science Food Agriculture, 33, 777-780.

Yan, L. H. (2009, April). Application of the $\mathrm{Al}_{2} \mathrm{O}_{3}$ - PVDF Nano Composite Tubular Ultrafiltration (UF) Membrane for Oily Wastewater Treatment and its Antifouling Research. Separation and Purification Technology. 